\title{
Hume: três problemas centrais
}

\author{
João Paulo M onteiro \\ Universidade de São Paulo/ Universidade de Lisboa
}

resumo 0 objetivo deste artigo é discutir três problemas centrais na filosofia de David Hume. 0 primeiro é 0 do papel da associação de idéias: no Tratado há dois conceitos distintos dessa associação, falha corrigida na primeira Investigação, em que é eliminado 0 conceito de "associação costumeira" e não se atribui à associação qualquer papel na formação de inferências causais. 0 segundo diz respeito ao verdadeiro papel da indução. A filosofia humeana trata da descoberta dos poderes causais dos objetos, sem nunca se ocupar de generalizações acerca de qualidades sensíveis. Hume descobriu o problema da "indução causal", mas apenas como conseqüência de sua análise da inferência causal. 0 último de nossos problemas é o do exato conceito humeano daquele instinto que ele chama de "costume ou hábito". 0 princípio de Hume mostra ser apenas uma sensibilidade à repetição de conjunções, sendo relevante apenas o elemento "repetição", sem haver qualquer influência significativa da passagem do tempo, 0 que impede a interpretação desse princípio como "habituação" ou algo equivalente.

palavras-chave causação - associação - indução - hábito - inferência - racionalidade

Pretendo aqui discutir três problemas centrais para a interpretação da filosofia de $\mathrm{D}$ avid $\mathrm{H}$ ume. $\mathrm{N}$ enhum deles recebeu adequada atenção por parte dos estudiosos dessa filosofia. 0 primeiro desses problemas diz respeito ao conceito de associação: no Tratado da natureza humana, de 1739, encontramos dois conceitos completamente distintos da associação de

R ecebido em novembro de 2004. A ceito em janeiro de 2005.

doispontos, Curitiba, vol. 1, n. 2, p.111-128, jan/ jun, 2005 


\section{2}

idéias, muito pouco compatíveis entre si, o que constitui uma daquelas negligências que mais tarde o próprio autor veio a reconhecer existirem nessa sua obra de juventude (H U M E, 1999, p. 83). Essa negligência foi corrigida na versão definitiva da teoria humeana da associação, na Investigação sobre 0 entendimento humano. 0 primeiro desses conceitos está presente em 1.1.4 (quarta seção da primeira parte do primeiro livro do Tratado (HU M E, 2000)). 0 segundo problema diz respeito ao verdadeiro papel da indução na referida Investigação: a segunda parte da quarta seção (4.2) completa a análise das inferências causais iniciada na primeira parte (4.1), mas a generalização da posse de qualidades sensíveis não-causais é nitidamente, embora de modo apenas implícito, recusada como problema filosófico a ser discutido. 0 terceiro problema diz respeito ao conceito humeano de nossa disposição inata para fazer inferências causais a partir de conjunções repetidas, um instinto a que ele chama "costume" ou "hábito" . A questão principal é que esse princípio, nos termos apresentados por $\mathrm{H}$ ume, depende unicamente da repetição, sem apresentar qual quer dependência relevante em relação ao tempo. Provavelmente é devido a essa razão que ninguém, a não ser $\mathrm{H}$ ume, tanto antes como depois dele, considera esse tipo de disposição como uma forma de hábito ou costume, embora nosso filósofo atribua-lhe a mesma natureza que os "outros hábitos" referidos no Tratado (1.3.9).

Essas são três questões difíceis e controversas. Todas elas são essenciais para a interpretação da epistemologia de $\mathrm{H}$ ume e todas elas deram origem a graves mal-entendidos. É natural que à primeira vista essas questões sejam consideradas estranhas, mas creio que o exame atento dos textos revela ser indispensável adotar uma atitude crítica perante a interpretação predominante da filosofia de $\mathrm{H}$ ume, que demasiado facilmente desemboca em acusações de associacionismo, indutivismo e psicologismo, a partir da crença nas perspectivas exatamente contrárias às que aqui são defendidas.

Para começar pelo primeiro de nossos três problemas, o da radical diferença entre os dois conceitos de associação de idéias que estão presentes no Tratado, é preciso examinar os textos com atenção. $R$ elativamente ao 
primeiro desses conceitos, $\mathrm{H}$ ume $(2000,1.1 .4 .1)$ afirma que existe "uma qualidade associativa devido à qual uma idéia natural mente introduz uma outra". E acrescenta: "Este princípio de união entre idéias não deve ser considerado uma conexão inseparável" ; "devemos apenas encará-lo como uma força suave, que geralmente prevalece"; acrescenta também que "as qualidades de onde derivam essas associações [...] são três, a saber, a semelhança, a contiguidade de tempo e lugar e a causa e efeito".

$\mathrm{N}$ a Parte 3 do mesmo livro do Tratado aparece um segundo conceito de associação de idéias. D epois de enfatizar que os princípios da semeIhança, da contiguidade e da causação são "os únicos princípios gerais que associam idéias" (idem, 1.3.6.13), o filósofo acrescenta no parágrafo seguinte esta inquietante afirmação: “ $H$ á certamente um princípio de união entre idéias que à primeira vista pode ser considerado diferente daqueles, mas que se verificará depender no fundo da mesma origem". A isso H ume aduz: "Q uando se constata através da experiência que cada indivíduo de uma qualquer espécie de objeto está constantemente unido a algum indivíduo de outra espécie, o surgimento de qualquer novo indivíduo de qualquer dessas duas espécies conduz o pensamento para seu acompanhante habitual" (idem, 1.3.6.14). Esse é claramente um novo conceito de associação, no qual o "princípio de união" não depende de qualquer semelhança, contigüidade ou causação, pois depende de um fator totalmente diferente: a união constante dos membros de duas classes de objetos em nossa experiência; sobre isso $H$ ume comenta que esse é "um verdadeiro princípio de associação entre idéias" (idem, 1.3.6.15).

A essas alturas, podemos imaginar que os primeiros leitores do Tratado fossem incapazes de ver que esse princípio parece-se muito com o hábito ou costume e que esse tipo de associação deve ser considerado uma "associação costumeira", radicalmente diferente do tipo de associação que é gerado pela semelhança, a contigüidade ou a causação. $M$ as dado que nada há de significativamente costumeiro no primeiro princípio de associação e, reciprocamente, que esse novo "verdadeiro princípio" não depende de qual quer daquelas três qualidades, mas apenas da repetição de conjunções, nós, que já lemos o resto do Tratado, além da Investigação sobre 0 entendimento, não podemos deixar de ver, pelo menos, que temos diante de nós dois conceitos de associação amplamente distintos. 


\section{4}

0 segundo conceito de associação é totalmente irredutível ao primeiro. É perfeitamente claro, em primeiro lugar, que ele nada tem a ver com a semelhança. $\mathrm{Q}$ uanto à contigüidade, diz $\mathrm{H}$ ume que tendemos a associar aqueles objetos que temos o "longo costume" de encontrar nessa situação (idem, 1.1.4.2), mas, nessa primeira aparição da palavra "costume", esse princípio não está ligado a qualquer espécie de inferência. Por último, o segundo conceito de associação que aparece no Tratado não pode ser confundido com a associação por causação - sendo que esse terceiro aspecto merece uma elucidação especial, nos termos que se seguem.

Vejamos. Q ualquer associação de idéias por causação, como a associa ção entre a idéia de uma dor e a da ferida que a produz - o principal exemplo dado por Hume da terceira forma de associação - é que já tenhamos a crença de que a segunda é causa da primeira, ou pelo menos que tenhamos chegado, por meio de um processo inferencial, a uma conclusão acerca da existência dessa relação causal. Seria absurdo admitir a possibilidade dessa associação se essa condição não se verificasse. A s feridas e as dores não são semelhantes e freqüentemente não são contíguas. A contece às vezes associarmos a idéia da primeira à idéia da segunda, de modo que a associação possa ser feita por causação e não por qualquer quarto princípio de associação de idéias, conforme é indicado no Tratado (idem, 1.3.6.13) e é explicitamente afirmado na Investigação (HUME, 1999, 3.3).

Além disso, o segundo desses conceitos está tão próximo do hábito ou do costume que não pode ser considerado uma "força suave", ao contrário do primeiro conceito. 0 contraste dificilmente poderia ser mais forte: nada há de "suave" na força do hábito que gera a crença causal, cuja ação é forte e irresistível, conforme lemos na Investigação: “Essa crença é o resultado necessário de colocar os homens em tais circunstâncias [experiência repetida]. É uma operação da alma, quando estamos nessa situação, tão inevitável como sentirmos a paixão do amor, quando recebemos benefícios, ou a do ódio, quando nos defrontamos com injúrias. Todas estas operações são uma espécie de instintos naturais, que nenhum raciocínio ou processo do entendimento seria capaz de produzir ou de evitar" (idem, 5.1.8). N ão posso deixar de pensar que isso elimina qualquer possibilidade de pretender que haja em $\mathrm{H}$ ume qual- 
quer derivação do raciocínio causal a partir dos três "suaves" princípios de associação.

Chegamos assim à conclusão de nosso primeiro ponto, que em síntese é a seguinte: na teoria epistemológica definitiva de $\mathrm{H}$ ume, apresentada na Investigação sobre 0 entendimento, o único conceito de associação de idéias que é apresentado não tem nem poderia ter qualquer papel direto na formação das crenças causais. Em outro lugar apresento uma argumentação mais completa a favor dessa leitura (M O N TEIR 0, 2003, cap. 1). A única maneira como se poderia conceber que a inferência causal e a crença causal poderiam derivar de alguma forma de associação é por meio daquela associação costumeira ambiguamente apresentada no Tratado, obra que o próprio autor declara ter sido publicada às pressas, além de no fim da vida recusar- se a assumi- la como representativa de sua filosofia. 0 Tratado é uma obra-prima, mas uma obra- prima cheia de negligências, as quais $\mathrm{H}$ ume lamenta na "A dvertência" que precede a edição das obras em que reformulou a sua filosofia (idem, p. 83, como vimos acima). São negligências de tal magnitude que nos obrigam a voltar-nos para a primeira Investigação como fonte mais confiável da epistemologia humeana, obra em que o único conceito de associação que é conservado não tem nem jamais poderia ter qualquer papel significativo na formação dos raciocínios e convicções causais.

\section{III}

Hume é geralmente celebrado pela descoberta daquilo que Popper chamou "o problema lógico da indução" (PO PPER , 1972, p. 3ff.). M as na segunda parte da secção 4 da Investigação sobre o entendimento, em que são apresentados os argumentos decisivos de H ume, o que realmente é discutido diretamente é uma questão mais restrita do que o problema da indução em geral. A quilo que H ume mostra nunca podermos" derivar da razão" são apenas as inferências causais, as quais evidentemente constituem uma parte essencial do problema geral da indução, mas apenas uma parte, não toda a questão em sua máxima generalidade. H ume nunca fala de inferências indutivas e jamais afirma que a indução em geral não pode ser derivada da razão - embora essa última conclusão deva ser 


\section{6}

considerada uma conseqüência inevitável de seu argumento negativo. Há uma passagem que é essencial para tornar claro esse ponto.

$\mathrm{N}$ a Investigação (HU M E, 1999, 4.2.16), aquilo que preocupa H ume é o problema da maneira como podemos descobrir os poderes e princípios causais da natureza, entendidos como "segredos" que a última esconde de nós. A natureza "proporcionou-nos apenas o conhecimento de umas tantas qualidades superficiais dos objetos" e o exemplo de H ume nessa passagem é que "nossos sentidos informam-nos da cor, do peso e da consistência do pão, mas nem os sentidos nem a razão poderão jamais informar-nos daquelas qualidades que o tornam adequado à nutrição e sustento do corpo humano".

Parece-me claro que essas passagens jamais poderiam ter sido escritas por um filósofo que estivesse interessado no problema geral da indução, sobretudo nos problemas relativos à generalização das qualidades sensíveis das coisas, como a cor ou o peso do pão. Aqui ou em qualquer outro lugar, $\mathrm{H}$ ume simplesmente não levanta qualquer questão acerca da possibilidade e das condições da possibilidade de chegarmos à descoberta de verdades universais acerca da posse dessas qualidades, tais como "todo pão tem a consistência $x$ " ou "o peso médio do pão é $y$ ". 0 que teríamos nesses casos seriam conclusões indutivas não-causais, como vários dos exemplos mais notórios da literatura epistemológica, "todos os corvos são pretos" e outros do mesmo gênero - Hume simplesmente parece não ter nada a dizer acerca desse assunto. 0 peso e a consistência são qualidades superficiais do pão cujo conhecimento é oferecido pela natureza e o problema da validade universal, se é que existe tal coisa, das proposições que exprimem esse tipo de conhecimento, é completamente ignorado por H ume.

Só pode ser devido a isso que os exemplos típicos das conclusões das inferências humeanas são todas do tipo "todo fogo causa calor" e não do tipo "todos os cisnes são brancos". 0 que H ume está discutindo, pelo menos diretamente, são as disposi çoes causais, como a disposição da neve para causar frio, e não qualidades sensíveis, como a fluidez da água (idem, 4.1.6) ou a consistência do pão (idem, 4.2.16). 0 que significa que Hume discute apenas uma forma de inferência indutiva, que é a inferência causal. Q uestões do tipo "como sabemos que a água é fluida?" ou "como sabemos que o pão tem um determinado peso médio?" ou "como sabemos que todos os corvos são pretos?" simplesmente não são examinadas 
em sua epistemologia, tanto na Investigação quanto no Tratado. Tudo se passa como se para Hume não existisse qualquer problema geral da indução e existisse apenas o que poderíamos chamar "o problema da causação" - ou talvez, se se preferir, "o problema restrito da indução"; ou seja, o problema da inferência causal encarado como uma entre outras formas de inferência indutiva. Torna-se assim inaceitável que Bertrand $\mathrm{R}$ ussell, por exemplo, acrescente à sua correta análise da teoria de $\mathrm{H}$ ume, discutindo as relações entre causas e efeitos, a afirmação de que uma das doutrinas de H ume é que "a indução por enumeração simples não é uma forma válida de argumento" e também admitir que essas doutrinas levam-nos à conclusão de que "a rejeição da indução torna irracionais todas as nossas expectativas de futuro" (R U SSELL, 1945, P. 693)1. H ume nunca discutiu a indução enquanto tal, mas apenas, conforme penso ter mostrado, a inferência causal e a crença causal.

Permitam-me insistir que o célebre argumento da quarta seção da Investigação (idem, 4.2), a respeito da impossibilidade de derivar da razão as inferências causais, também pode ser aplicado a outros tipos de inferência indutiva. $\mathrm{N}$ ão há dúvida de que os argumentos humeanos acerca da inferência causal também se aplicam à indução por enumeração em geral. $M$ as essa foi a conclusão, aliás fundamentalmente correta, de sua posteridade e simplesmente não é verdade que $\mathrm{H}$ ume tenha conscientemente discutido a indução como tal.

0 conjunto de todas as inferências causais pode ser concebido como um círculo mais restrito no interior do círculo mais amplo formado pelo conjunto de todas as inferências indutivas e talvez possamos dizer que H ume, ao descobrir que as inferências causais não podem ser derivadas da razão, ao contrário das conclusões dedutivas (como, por exemplo, que a soma dos ângulos internos de um triângulo perfaz 180 graus), também levantou o véu do problema escondido de que a indução em geral também não pode ser derivada da razão. $M$ as nada nos autoriza a supor que ele tivesse a intenção de colocar em xeque a indução em geral, porque sua intenção era, antes de mais, investigar o círculo restrito das inferências causais e, depois, apresentar sua teoria acerca do hábito ou costume e da experiência repetida como fontes da inferência causal.

A lém disso, se prestarmos a devida atenção ao caráter dos exemplos humeanos de inferências e crenças causais, podemos constatar que esses 


\section{8}

exemplos traçam um círculo mais restrito, conforme vimos, do que 0 conjunto de todas as inferências indutivas, mas que além disso elas desenham um círculo ainda mais restrito no interior do próprio círculo das inferências causais: o círculo das relações causais que são independentes das incertezas de todos os tipos de comportamento, animal ou humano, individual ou social. Vejamos com atenção os exemplos da primeira parte da quarta secção da Investigação que preparam e sustentam o famoso "argumento negativo" de H ume acerca da causação: 1) "O sol vai nascer amanhã" (idem, 4.1.2); 2) "Alguém que ache um relógio ou qualquer outra máquina numa ilha deserta concluirá que alguma vez estiveram homens nessa ilha" (idem, 4.1.4); 3) "O uvir uma voz articulada e um discurso racional no escuro assegura nos da presença de alguma pessoa" (ibidem); 4) "O calor e a luz são efeitos colaterais do fogo" (ibidem); 5) "A água [...] sufocaria [A dão, nesse exemplo] e o fogo o consumiria" (idem, 4.1.6); 6) "D uas peças lisas de mármore [...] irão aderir uma à outra de maneira a precisarem de uma grande força para separá las em linha reta, embora oponham pouca resistência a uma pressão lateral" (idem, 4.1.7); 7) "A explosão da pólvora" (ibidem); 8) "A atração do magneto" (ibidem); 9) "O pão é alimento adequado para um ser humano, mas não para um leão ou para um tigre" (ibidem); 10) "U ma bola de bilhar comunica movimento a uma outra após impulso" (idem, 4.1.8; cf. idem, 4.1.10); 11) "U ma pedra ou um pedaço de metal, lançados ao ar e deixados sem qualquer suporte, caem imediatamente" (idem, 4.1.9); 12) "A elasticidade, a gravidade, a coesão de partes e a comunicação do movimento por impulso são provavelmente as causas e princípios últimos que jamais descobriremos na natureza" (idem, 4.1.12); 13) "O momento ou força de qualquer corpo em movimento é a razão composta, ou proporção, de seu conteúdo sólido e de sua velocidade" (idem, 4.1.13); 14) "0 cristal é um efeito do calor e o gelo, do frio" (ibidem).

0 elemento comum a todos esses caso se que eles são exemplos de leis da naturez a ou de operaçoes de corpos (idem, 4.1.9). N ão há um único que seja, por exemplo, uma sensação causando uma emoção ou uma ameaça causando um determinado comportamento ou qualquer uma das relações causais mais incertas, como aquelas que na secção 6 são chamadas "probabilidades", em contraste com o que Hume chama "provas" como, por exemplo, que "todos os homens têm de morrer" ou o já referi- 
do "o Sol nascerá amanhã" (idem, 6, nota). E, evidentemente, não há entre eles um exemplo sequer de relação entre objetos e suas qualidades sensíveis - ou seja, nada acerca da indução em geral, mas apenas acerca da descoberta de poderes causais.

\section{IV}

N osso terceiro e último problema diz respeito ao exato conceito, nos textos de H ume, daquele princípio da natureza humana que nos torna capazes de fazer inferências causais. $\mathrm{N}$ osso filósofo decidiu dar os nomes de "costume" ou "hábito" ao instinto que nos dá essa capacidade. O s mesmos dois termos haviam sido ocasionalmente utilizados por outros filósofos, em um ou outro dos sentidos mais usuais que esses termos tinham na linguagem comum. Para Locke, por exemplo, a "idéia" de hábito é a de "um poder ou capacidade que uma pessoa tem de fazer alguma coisa, quando esse poder foi adquirido por freqüente [sic] fazer essa mesma coisa" (LO C KE, 1959, II .xxii.10, p. 293). Fica aqui estabelecido um contraste com o conceito humeano de costume ou hábito como consistindo, mais do que simplesmente em uma capacidade, em uma efetiva propensão para fazer alguma coisa que já foi repetidamente feita: "sempre que a repetição de algum ato ou operação particular produz uma propensão para realizar outra vez esse ato ou operação, sem que seja impelido por qualquer raciocínio ou processo do entendimento, sempre dizemos que essa propensão é efeito do costume" (HU ME, 1999, 5.1.5).

Locke e H ume olharam, cada um deles, para um de dois aspectos da mesma disposição - não há aqui qualquer diferença importante entre "costume" e "hábito" - sendo que o primeiro desses filósofos enfatizou uma capacidade ou competência e o segundo uma propensão ou tendência (ou "instinto" (idem, 5.2.22)), mas essa não é a diferença mais significativa entre ambos. N o caso de Locke a ênfase recai sobre a freqüência e no caso de $H$ ume ela recai sobre a repetição. $M$ as não serão estas a mesma coisa? Bem, sim e não, dependendo do contexto e da perspectiva - e acontece que no presente caso há uma diferença filosófica bastante importante, no fato de o conceito que Hume tem de seu princípio 


\section{0}

incluir, par excellence, aqueles casos em que unicamente a repetição é relevante e não a repetição no tempo, como é o caso em Locke e talvez em todos os usos possíveis dos termos " costume" ou "hábito" antes de H ume.

Examinem-se os principais exemplos da operação do princípio humeano do hábito ou costume oferecidos na Investigação: o choque de duas bolas de bilhar, uma pedra jogada no ar e depois caindo, a sucessão do fogo e do calor ou da neve e do frio (idem, 5.1) e outras "conjunções constantes". Em todos esses casos, apenas a repetição é necessária para que o princípio de $\mathrm{H}$ ume opere plenamente. $\mathrm{N}$ ão quero dizer aqui que nosso filósofo estivesse ou devesse estar consciente disso, mas apenas que seu conceito de seu próprio princípio era o de uma "sensibilidade", própria da natureza humana, à observação de conjunções repetidas e não uma sensibilidade à experiência do tempo enquanto tal. É certamente evidente que nenhuma experiência é possível a não ser que transcorra no tempo, qualquer que seja a duração. M as em alguns casos a passagem do tempo é o elemento relevante e em outros casos o elemento relevante é a repetição. Em H ume só conta este último fator como núcleo central do significado de seu célebre princípio.

Do que estava nosso filósofo realmente falando aqui? Ele falava de uma disposição que todos nós temos, a disposição para derivar, a partir da repetida concomitância de dois objetos em nossa experiência, a predição da mesma conjunção nas futuras experiências que deles viremos a ter. Se lançarmos um dado cinqüenta vezes seguidas e em todos esses casos o resultado for um número ímpar, concluímos sem a menor hesitação que esse objeto sempre se comportará da mesma maneira e esperaremos que, da vez seguinte, talvez em todos os futuros lances do mesmo dado, saia também um número ímpar. A pergunta essencial a colocar aqui é esta: será isso um efeito do hábito, no sentido corrente desse termo? Talvez $\mathrm{H}$ ume respondesse afirmativamente. $M$ as muita gente, talvez incluindo L ocke, daria uma resposta negativa, independentemente de sua aceitação ou rejeição da teoria humeana da inferência causal.

Seria possível e legítimo, na época de Hume ou na nossa, aceitar a teoria humeana segundo a qual a inferência e a crença causal derivam da experiência de conjunções repetidas, assim como a negação de que tudo isso pudesse derivar da razão (se concebermos essa faculdade como uma capacidade dedutiva e essa capacidade como "insensível à repetição" ) e ao 
mesmo tempo rejeitar a teoria de H ume acerca da derivação da inferência causal do hábito ou costume. Vejamos em que termos H ume argumenta contra a explicação pela razão das inferências por meio da repetição: "A razão é incapaz de qualquer variação como essa. As conclusões que ela tira do exame de um único círculo são as mesmas que ela formaria após examinar todos os círculos do universo" (idem, 5.1.5). Essa "incapacidade de variação" ou, como também podemos dizer, essa "insensibilidade" da razão à repetição constitui 0 argumento decisivo de Hume em favor da eliminação da razão dedutiva como verdadeiro princípio da inferência causal. 0 conceito de razão com que nosso filósofo trabalhava, que era o conceito vivo de razão vigente em sua época, não era adequado para dar conta de qualquer tipo de processo de que a repetição fosse um aspecto essencial.

O ra, no conceito humeano do princípio da natureza humana responsável pela inferência causal podemos encontrar a mesma "insensibilidade" - uma completa indiferença à ação do tempo no processo que Hume investiga à luz desse princípio. $\mathrm{N}$ a experiência causal como a apresenta nosso filósofo, independentemente, mais uma vez, de ele ter ou não consciência disso, a repetição é o único fator relevante. Em nosso exemplo do jogo com um dado, mas também nos exemplos que ele próprio apresenta do impulso ou do movimento, do lançamento e queda de corpos, do fogo seguido de calor ou da neve produzindo frio, o que conta é exclusivamente a repetição, nunca a passagem do tempo. 0 elemento decisivo é o número de repetições - ninguém sabe quantas, mas todo mundo sabe que há um limite - e não a duração de cada experiência. Se lançando um dado saírem números ímpares cinqüenta vezes em cinqüenta segundos, ou se o fogo for seguido de calor cinqüenta vezes em cinqüenta minutos, ou vice-versa, estaremos perante experiências ampla mente suficientes para permitirem inferências causais, tanto quanto se fossem cinqüenta vezes em cinqüenta horas ou, por absurdo, aprender alguma coisa em cinqüenta anos através da observação da mesma conjunção uma vez por ano! M as mais absurdo do que isso seria, creio eu, insistir que o princípio humeano de inferência tivesse intrinsecamente alguma coisa a ver com a passagem do tempo - para além da óbvia neces sidade de um mínimo de tempo para poder-se ter qualquer tipo de experiência repetida. 
Será isso o que todos entendemos por costume ou hábito? Bem, certamente não é aquilo que eu entendo ao ouvir esses termos. $\mathrm{M}$ eu conceito de hábito é, segundo creio, o conceito comum: o conceito de uma disposição para adquirir capacidades ou tendências pela ação do tempo em nossos corpos, em nossas mentes ou em ambos. C reio também que era esse 0 conceito comum na época de $\mathrm{H}$ ume e que durante essa época, ou antes dela, o conceito de costume ou hábito jamais envolveu processos exclusivamente derivados da repetição, sem qualquer influência do tempo. 0 hábito era e ainda é uma sensibilidade à influência do tempo - mesmo sem repetição. Se eu passar vários dias em algum lugar sob calor constante, ou sob frio constante, sem haver interrupções e portanto sem realmente haver repetição, irei acostumar-me ou habituar-me ao calor ou ao frio pelo menos tanto quanto no caso de eu sofrer essas temperaturas a intervalos, ou seja, por experimentá-los repetidamente. Em nosso conceito comum da influência do hábito, a repetição pode ser dispensável, enquanto o tempo é o aspecto realmente indispensável para sentirmo-nos autorizados a falar da ação do costume.

0 que foi que nosso filósofo realmente fez quando apresentou sua teoria acerca da origem da inferência e da crença causal? A credito que podemos admitir com segurança que ele expandiu, ou procurou expandir, o conceito de hábito ou costume - e que talvez ele tenha feito isso sem o saber. Ele propôs a seus leitores que algo deve ser aceite como legítimo exemplo da influência do hábito simplesmente por derivar da repetição, conforme claramente assevera na I nvestigação (idem, 5.1.5), como acima foi visto. Isso equivale a propor tacitamente um conceito ampliado de hábito, entendido como uma disposição para ser influenciado pelo tempo ou apenas pela repetição, ou por ambos - sendo a segunda dessas possibilidades, evidentemente, inteiramente nova nesse conceito.

Tanto quanto sei, o conceito de hábito não sofreu mudanças significa tivas desde a época de H ume. A repetição continua sendo considerada por todo mundo um fator plausível nos processos de habituação apenas quando também está presente 0 tempo - a idéia de alguém realmente se acostumar a alguma coisa em cinqüenta segundos é simplesmente disparatada. Suponho que seja possível alguém tornar-se vidado em alguma droga em alguns segundos, mas mesmo que tal seja realmente possível, ninguém dirá que a pessoa acostumou-se à droga ou que o vício é 
realmente um efeito do hábito. 0 que se dirá é que houve algo muito diferente: em alguns casos, simplesmente dependência física de uma droga, nunca hábito - e costume talvez ainda menos.

Tudo isso pode até constituir um fator negativo entre os leitores de H ume, como obstáculo à aceitação da razoabilidade de sua teoria da inferência causal. Talvez algumas pessoas "sintam" que o que acontece com elas quando aprendem alguma coisa, mesmo quando esse aprendiza do faz-se por meio de uma experiência repetida, não depende da duração do tempo despendido no processo, tornando-se assim implausível que ele realmente dependa do hábito. Bem sei que houve pessoas muito especiais, como Bertrand $\mathrm{R}$ ussell, que adotaram uma ou outra versão dessa teoria. Em A n 0 utline of Philosophy, de 1927, há um capítulo intitulado "A inferência como hábito" (RU SSELL, 1927, p. 82ff.)2. M as o que R ussell entendia aqui por "hábito" tinha a ver com reações corporais e reflexos condicionados, sendo Hume referido apenas como autor de argumentos céticos acerca da indução, sem qualquer referência direta a seu conceito de costume ou hábito (idem, p. 83-84). N ão encontrei em parte alguma qualquer sinal de alguém ter a crença inequívoca de que 0 hábito pode ser concebido independentemente do fator temporal.

O utro aspecto importante do princípio humeano da inferência causal é que seus efeitos na mente humana são inevitáveis, coisa que nem sequer poderia jamais ser sonhada no caso do hábito, digamos, "tradicional". A Investigação é perfeitamente inequívoca quanto a isso: esse "instinto ou tendência mecânica" é "infalível em suas operações" (HUME, 1999, 5.2.22). A crença causal é, como vimos acima, o resultado necessário da observação de conjunções constantes, uma inescapável operação do espírito humano (idem, 5.1.8). Ficamos assim bem longe do espaço do verdadeiro hábito ou costume, no qual, conforme sabemos, o máximo que podemos ter são indinações para certos cursos de ação ou pensamento, mas nunca a ponto de alguém ficar totalmente incapaz de evitá-los. Portanto há alguma coisa mais, além da independência em relação ao tempo, que a teoria humeana estaria implicitamente tentando acrescentar ao conceito comum de hábito: a possibilidade, em alguns casos, de conseqüências forçosas e realmente inevitáveis desse princípio.

0 princípio causal de Hume é um princípio especial e uma chave essencial - a juntar à constatação de que nenhuma irracionalidade asso- 


\section{4}

ciativa intromete-se no processo inferencial, bem como à descoberta de que H ume só discutiu a inferência causal e não as inferências indutivas em geral - para a compreensão de sua epistemologia como uma filosofia da racionalidade. Essa palavra não era usada no tempo de nosso filósofo embora o fosse um termo como "razoabilidade", assim como o adjetivo "racional" - de modo que a racionalidade não era discutida com esse nome. $\mathrm{M}$ as $\mathrm{H}$ ume jamais disse, ou sequer sugeriu, que a inferência causal, como ele sempre chamou aquilo a que outros preferem chamar "indução", fosse irracional ou desrazoável. Ele apenas demonstrou, em um sentido forte desse termo, que seria ilógico tentar derivar esse tipo de inferência da razão dedutiva clássica. Há até mesmo uma passagem, pelo menos, com a forte sugestão de que $\mathrm{H}$ ume sequer jamais sonhou que qualquer autêntica inferência causal pudesse deixar de ser raz oável. Q uando, na Investigação, al ega que uma pessoa sem qualquer experiência anterior nunca seria capaz de inferir uma relação causal a partir da experiência de uma conjunção isolada ou singular, ele acrescenta o seguinte: “ $N$ ão é razoável concluir, meramente porque numa determinada ocasião um evento precede outro, que portanto um deles é a causa e 0 outro 0 efeito. [...] Pode não haver razão para inferir a existência de um do aparecimento do outro" (idem, 5.1.3; sem grifos no original). Parece-me que nesse caso a inevitável conclusão acerca do sentido e da intenção do texto humeano é que, quando um acontecimento repetidamente precede outro, há uma boa raz ão para concluir que ele é sua causa, se não houver argumentos contrários a isso e que, nesse caso, essa é a única conclusão razoável que pode ser tirada.

$M$ as em que sentido as conjunções repetidas observadas podem constituir boas razões? Esse é um caso em que "bom" não pode qualificar as razões como sinônimo de "válido", em qualquer sentido lógico ou dedutivo. Q uais são os outros sentidos desse termo? N ão se pode tratar de um sentido "psicológico", porque nesse caso não teríamos propriamente boas razões. $M$ as a conjunção repetida de dois fenômenos pode ser considerada uma boa razão para rejeitar a hipótese de que essa concomitância, tanto nos casos observados quanto de um modo geral, poderia ser inteiramente devida ao acaso.

$\mathrm{N}$ em H ume nem qualquer de seus contemporâneos estava na posse de qualquer autêntica teoria das hipóteses ou conjecturas 3 e, por outro 
lado, $\mathrm{H}$ ume sustentava o ponto de vista oficial segundo o qual "o que 0 vulgo chama acaso não é mais do que uma causa secreta e escondida" (H U M E, 2000, 1.3.12.1; cf. H U M E, 1999, 6.1). Pouco ou nenhum lugar havia na filosofia para quaisquer teorias acerca das hipóteses e do acaso ou de hipóteses de acaso. $M$ as não podemos esquecer que seu princípio causal era eminentemente um princípio de sobrevivência e que, se a humanidade sobreviveu, foi porque, assim como outras espécies, possui uma capacidade mental para distinguir entre aquelas conjunções de fenômenos que são casuais e irrelevantes e aquelas que são causais, tendo algumas destas últimas uma importância vital. Hume nunca seguiu esse caminho4, mas por aqui poderíamos ter uma maneira possível de argumentar que uma conjunção suficientemente repetida constitui uma boa razão - uma boa razão para pôr de lado e eliminar a hipótese de que a conjunção em questão se deve inteiramente ao acaso. Por outro lado, H ume afirma explicitamente que não é razoável tirar conclusões precipitadas a partir de qualquer conjunção solitária porque ela" pode ser arbitrária e casual" (H U M E, 1999, 5.1.3). Isso significa que essa conjunção poderia ser um "encontro de acaso" e implica que a repetição vem revelar que realmente não o é.

É com grande freqüência que temos a experiência de conjunções de fenômenos de toda a espécie e a maior parte delas são conjunções fortuitas: simplesmente ocorre que um cachorro lata ao longe imediatamente depois de eu entrar por uma porta ou que eu escute um trovão logo depois de eu fechar essa porta, para limitar-me aqui a exemplos de conjunções entre atos e sons. Mas há milhões de outros casos de conjunções, a todo instante, quase todos eles sem qualquer ligação entre si, sendo apenas alguns poucos os que representam algum tipo de conexão causal. A teoria de H ume é que só podemos descobrir os que representam conexões causais por meio da observação das repetidas conjunções entre esses fenômenos ligados, que só aprendemos que eles estão conectados por meio de suas conjunções constantes ou freqüentes e esse grande princípio é a sensibilidade à repetição dessas conjunções. Talvez ele concordasse que, se todas as conjunções, sem exceção, produzissem expectativas em nós, ficaríamos submergidos em um mundo mental caótico e que, se nenhuma o fizesse, seríamos liquidados pela primeira conjunção letal que atravessasse nosso caminho. 0 princípio de 


\section{6}

H ume, distinguindo algumas delas - mas apenas aquelas que se repetem suficientemente -, situa-se em um conveniente terreno intermédio, como instrumento de sobrevivência.

0 princípio de $\mathrm{H}$ ume é claramente um princípio de racionalidade. Além da "racionalidade dedutiva", exemplificada em sua época pelas ciências matemáticas, mas na qual creio que ele não hesitaria em incluir a lógica formal, uma forma de racionalidade que ele encontrava no domínio das puras "relações de idéias" - além dessa havia uma outra forma de racionalidade muito diferente, a ser encontrada na descoberta das regularidades do mundo natural. Q uando na I nvestigação ele declara sua intenção de descobrir "a natureza daquela evidência que nos assegura de qual quer existência real e questão de fato" para além do testemunho dos sentidos e da memória (idem, 4.1.3), ele anuncia sua busca de uma nova fonte de racionalidade, para substituir a velha fonte que outros imaginavam possuir sob a forma da razão clássica. Esse era um sonho demonstravelmente impossível. $\mathrm{N}$ ão estou certo de que o sonho de H ume seja demonstravelmente possível - mas que bem poderia sê-lo é, segundo creio, aquilo que a epistemologia contemporânea tem-se esforçado por estabelecer.

Tomados em conjunto, esses três pontos da filosofia de $\mathrm{H}$ ume devem levar-nos à concepção de sua teoria da inferência causal como 0 exato oposto daquilo que nos apresentam as interpretações que a reduzem a uma psicologia ou coisa equivalente, que têm um de seus exemplos mais extremos na distinção de Popper entre dois problemas da epistemologia humeana, um deles "lógico" e o outro "psicológico" (PO PPER , 1972, p. 3). Espero ter deixado claro que nada disso faz sentido como interpretação de H ume. Em primeiro lugar, a teoria humeana não assenta, em sua forma definitiva, em qualquer espécie de "psicologia associacionista" , mas em uma linha argumentativa inteiramente diferente. Em segundo lugar, Hume jamais poderia tornar-se suspeito de qualquer "indutivismo psicológico", na medida em que o seu tema é o raciocínio causal e não as inferências indutivas de qualquer tipo não-causal. Em terceiro lugar, 0 
uso dos termos "costume" e "hábito" exprime apenas uma escolha de termos feita por H ume e não significa que seu conceito do princípio da natureza humana que considerava responsável pelas inferências causais seja um conceito "psicológico", em contraste com o sentido que geralmente atribuímos ao conceito de costume ou hábito - é uma disposição cognitiva inata, independente do tempo e ligada exclusivamente às conjunções repetidas de fenômenos.

Esses três problemas centrais devem-se em parte à falta de cuidado do jovem Hume ao escrever o Tratado, à extrema complexidade de sua filosofia em geral e às conclusões apressadas de alguns intérpretes, apesar de al guns deles serem grandes filósofos, como R ussell e Popper. A tentativa aqui feita, de tornar mais claros esses problemas, poderá, segundo espero, contribuir para uma melhor compreensão da epistemologia de D avid H ume e também para uma visão mais nítida da grandeza de sua filosofia.

1 Tomo aqui como tema uma parte do argumento que apresentei em meus $\mathrm{N}$ ovos estudos humeanos (M O N TEIR O, 2003, cap. 5).

2 R etomo aqui alguns dos argumentos que apresentei em meus $\mathrm{N}$ ovos estudos humeanos (MON TEIRO, 2003, cap. 2).

3 Ver meus textos: M onteiro (1981; 1984, cap. 1).

${ }^{4}$ Ver meus textos: M onteiro (1994; 2003, cap. 6).

\section{Referências bibliográficas}

H U M E, D. 1999. A n E nquiry concerning H uman U nderstanding. Ed. by Tom L Beauchamp. 0 xford: 0 xford U niversity. 2000. A Treatise of H uman $\mathrm{N}$ ature. Ed. by David Fate $\mathrm{N}$ orton and $\mathrm{M}$ ary J. $\mathrm{N}$ orton. $\mathrm{O}$ xford: $\mathrm{O}$ xford $\mathrm{U}$ niversity.

LO CKE, J. 1959. A n E ssay C oncerning H uman U nderstanding. Ed. by A. C. Fraser. $N$ ew York: D over. 


\section{8}

M O N TEIR O, J. P. 1981. H ume's C onception of Science. Journal of the $\mathrm{H}$ istory of Philosophy, D urham, v. XIX, n. 3, July.

_-_-_. 1984. H ume e a E pistemologia. Lisboa: Imprensa N acional. 1994. Chance, Induction and R ationality. In:VILLAN U EVA, E. (ed.). Truth and $R$ ationality. A tascadero: $R$ idgeview. . 2003. N ovos estudos humeanos. São Paulo: Discurso.

PO PPER , K. R . 1972. 0 bjective K nowledge. 0 xford: Clarendon.

RU SSELL, B. 1927. A n 0 utline of Philosophy. London: George Allen \& Unwin. 1945. T he H istory of W estern Philosophy. London: Simon and Schuster. 